\title{
METHYLENE BLUE ADSORPTION FROM GLYCEROL SOLUTION ONTO THE ACICULAR HABIT OF $\alpha$-GOETHITE
}

\author{
S.M.J. Zubairu ${ }^{1 *}$, A. Uzairu ${ }^{1}$, J.F Iyun ${ }^{1}$, S.E. Abechi ${ }^{1}$ and J.O. Okunola ${ }^{2}$ \\ ${ }^{1}$ Chemistry Department, Ahmadu Bello University, Zaria, Kaduna State, Nigeria \\ ${ }^{2}$ National Institute for Chemical Technology, (NARICT) Basawa, Zaria, Nigeria
}

(Received December 10, 2009; revised October 19, 2010)

\begin{abstract}
The mechanism of methylene blue adsorption onto the surface of synthetic acicular habit of $\alpha$ goethite from glycerol solution has been studied through batch experiment at 25,30 and $35{ }^{\circ} \mathrm{C}$ in a glass cell of minimal dead volume. To describe the adsorption results, an attempt was made to fit the data to the Langmuir, Freundlich, Temkin and Dubinin equations. It was evident that adsorption capacity increased rapidly from 4.7 to $27.2 \times 10^{-5} \mathrm{M}$ for the equilibrium concentration of 0.13 to $1.90 \times 10^{-5} \mathrm{M}$ at $25^{\circ} \mathrm{C}$ to a maximum of $33.1 \times 10^{-5} \mathrm{M}$ for $30^{\circ} \mathrm{C}$ for equilibrium concentration of $2.74 \mathrm{M}$. Drop in the height of the plateau was observed and remained unchanged for $35{ }^{\circ} \mathrm{C}$, and a maximum appeared in each isotherm before plateau. The adsorption process was found to be exothermic with an estimated mean entropy change of $23.84 \mathrm{~kJ} / \mathrm{mol}$. Also, an initial estimation of the surface acidity was made and it has been suggested that the surface of this mineral is heterogeneous if the location of these sites are presumed to be the adsorption sites identified as Lewis and Bronsted acid types. Furthermore, thermodynamic parameters $\Delta \mathrm{H}, \Delta \mathrm{G}$ and $\Delta \mathrm{S}$ for the adsorption were determined from the data and some features of the adsorption mechanism were enumerated on the basis of reaction scheme that incorporates simple adsorption phase exchange at the glycerol/ $\alpha-\mathrm{FeOOH}$ interface.
\end{abstract}

KEY WORDS: Surface interface, Crystal habit, Heterogeneity, Micropore volume

\section{INTRODUCTION}

$\alpha$-Goethite is a hydroxide of iron corresponding to the formulae $\alpha$-FeOOH, a common adsorbent in lateritic soil. The recognition of the presence of two habits of goethite was indicated by Atkinson et al. [1], thus the synthesis could be nucleated into two crystal habits. Crystal habit is the gross geometrical shape of a crystal and is governed by the different rates of growth of the various faces that bound the crystal. The growth of certain face may be preferred over the other and the shape of the growing crystals is determined by the presence or absence of dominant growing direction. These habits that present different crystal faces could differ as geosorbents. However, to our knowledge there are no reports on the synthesis of the acicular habit and no studies of their adsorption characteristic have been reported using organic solvent.

Many studies have shown that simple adsorption from water/adsorbent interface could be obscured by many surface interactions and many complexation/precipitation model have been proposed. Keeping in mind a possible simple ionization/dissociation reaction of proton and hydroxyl ions in aqueous solution, it was thought that the adsorption of ions from less polar solvent than water might limit these surface interactions. The solvent of interest is glycerol, a structured solvent (high dielectric constant) of fairly moderate molar mass, and capable of organizing solute, so that $\mathrm{MB}$ adsorption equilibria in glycerol on to the habit might be solventassisted. Methylene blue (MB) was chosen as adsorbate because of its strong adsorption onto solids and its recognized usefulness in characterizing adsorptive materials [2].

In our previous research [3], the adsorption of methylene blue from glycerol solution on twin habit of $\alpha$-goethite was interpreted in term of a monolayer model with edgewise orientation of MB on the surface of twin habit, and an attempt was made to correlate the trend observed with some adsorption model. The thermodynamics of adsorption were also discussed. In this work, the adsorption of MB on acicular habit morphology was examined in the same manner.

*Corresponding author. E-mail: mrmj_zubairu@yahoo.com 


\section{EXPERIMENTAL}

The acicular habit of $\alpha$-goethite were synthesized following the method of Atkinson et al. [1] or acicular morphological type of sample $1 \mathrm{c}$. The reagents used were identical to those described previously [3]. The adsorbent was dried at $100{ }^{\circ} \mathrm{C}$ for $2 \mathrm{~h}$ before use and then kept in a desiccator. The solvent glycerol was purified by fractionally distilled and dried over phosphorus pentoxide. Measured refractive index was $\mathrm{n}_{\mathrm{D}}{ }^{20}=1.472$; lit. value, 1.471-1.174.

\section{Quantitative determination}

Sample in $\mathrm{HCl}$ solution was reduced to $\mathrm{Fe}^{2+}$ with $\mathrm{SnCl}_{2}$ and titrated against a standard $0.0167 \mathrm{M}$ $\mathrm{Cr}_{2} \mathrm{O}_{7}{ }^{2-}$ solution in the presence of $1 \%$ diphenylamine as indicator.

\section{Infrared investigation}

The preparation of sample and spectroscopic techniques were identical with those used in our previous work [3].

A Genesis II Fourier Transform infrared spectrometer was used to record the spectra. Instrument was frequently calibrated against known standard. All spectra were recorded at room temperature.

\section{$X$-ray diffraction studies}

The powdered patterns for the acicular habit were obtained from method previously described [3].

\section{Adsorption from solution}

A special glass cell of minimal dead volume was designed and constructed in the glass blowing workshop of the Department of Chemistry, Ahmadu Bello University, Zaria, Nigeria, for the adsorption studies. This has been previously described [3].

Analyses of the adsorbates were done spectrophotometrically. The drop in concentration of solute (MB) in glycerol solution per unit mass of adsorbent plotted against the concentration of the solute. The specific surface area of the habit was estimated from $X_{m}$ and the cross-sectional area per molecule $\mathrm{A}_{\mathrm{m}}$ using the relation [4]:

$$
S=X_{m} \cdot N_{A} \cdot A m \cdot 10^{-20} / M
$$

where $X_{m}$ is monolayer coverage in mol/g of adsorbate from the isotherm.

$A_{m}$ is the occupied surface area of one molecule of $M B$ in the completed monolayer. $N_{A}$ is Avogadro's number, $6.02 \times 10^{23} \mathrm{~mol}^{-1}$ and $\mathrm{M}$ is the molecular wt of $\mathrm{MB}(373.9 \mathrm{~g} / \mathrm{mol})$. For monolayer coverage estimation it is assumed that the plateau on the isotherm do indicate the completion of monolayer coverage at least for this adsorbate. The point when the extrapolated linear plot cut the adsorption at equilibrium concentration equals zero was taken as $\mathrm{X}_{\mathrm{m}}$

In order to use the above formula (equation 1), it is necessary to know the value of the crosssectional area, $\mathrm{A}_{\mathrm{m}}$, of adsorbate molecule. Brunauer et al. [5] proposed that $\mathrm{A}_{\mathrm{m}}$ can be calculated from the density of the adsorbate in the liquid form as

$$
A_{m}=f\left(\frac{M}{d N}\right)^{2 / 3} 10^{16}
$$


where $\mathrm{f}=$ packing factor, the value of which depend on the number of nearest neighbour. $\mathrm{M}$ is the molecular wt of MB (373.9 $\mathrm{g} / \mathrm{mol})$; $\mathrm{N}$ is Avogadro's number; and d is the adsorbate density. For a common arrangement, the value of $f$ equals to 1.091 [4].

In order to ascertain the existence of microporosity, method of Dubinin Polanyi potential theory [6] was utilized in which the volume of the adsorption space was expressed as a Gaussian function of the corresponding adsorption potential. In principle, therefore the equation provides means for the assessment of micropore volume from the low concentration part of the type 1 isotherm. On the basis of which $\log$ of fractional coverage, $\mathrm{W}(\mathrm{x} / \mathrm{m})$ was related with $\log$ of $\left(\mathrm{C}_{\mathrm{O}} / \mathrm{C}\right)^{2}$. The total micropore volumes estimated from the intercept of Dubinin's equation (equation 3 ) equal to $\log \mathrm{W}_{\mathrm{O}} \mathrm{d}$.

$$
\left.\log w=\log w_{0} d-D \log C_{0} / C\right)^{2}
$$

On the basis of Everett's [7] thermodynamic theory of adsorption from solution we proposed this reaction scheme

$$
(M B)^{l}+(G)^{S} \stackrel{K_{a d}}{\rightleftharpoons}(M B)^{S}+(G)^{l}
$$

where $(\mathrm{MB})^{\mathrm{s}}$ and $(\mathrm{MB})^{1}$ are the methylene blue on the surface and in the bulk phase; $(\mathrm{G})^{1}$ and $(\mathrm{G})^{\mathrm{s}}$ are the glycerol on the surface and in the bulk phase, respectively. The equilibrium constant, $\mathrm{K}_{\text {ad }}$ given by equation 5

$$
K_{a d}=\frac{\left[M B^{s}\right]}{\left[M^{1}\right]}
$$

where $\left[\mathrm{MB}^{\mathrm{s}}\right]$ and $\left[\mathrm{MB}^{\mathrm{l}}\right]$ are the equilibrium concentrations of component 1 (methylene blue) in the surface and in the bulk liquid phase, respectively.

Thermodynamic parameters such as change in Gibbs energy $\Delta \mathrm{G}$ is related to equilibrium constant as

$$
K_{a d}=e^{-\triangle G / R T}
$$

where $\mathrm{R}$ is universal gas constant, $\mathrm{T}$ the absolute temperature in Kelvin and $\mathrm{K}_{\mathrm{ads}}$ is the thermodynamic equilibrium constant calculated using equation (5).

The overall free energy change as observed by Groskek [8] and Crisp [9] on adsorption involves the change in the Gibbs energy for concentration change taking place at the interface as well as for those taking place in the bulk phase. Therefore, considering a solid adsorbent (acicular $\alpha-\mathrm{FeOOH}$ in this case) is being brought into contact with a binary liquid solution, the change in Gibbs energy which occurs when adsorption equilibrium has been established for any one of the component, can be represented as

$$
\triangle G=-R T \ln \left[\overline{M B^{\prime}}\right]
$$

The temperature dependence of $\mathrm{K}_{\text {eqm }}$ could be used to determine the enthalpy of adsorption from solution [10], that: 


$$
\frac{\mathrm{d} \operatorname{lnK}}{\mathrm{d} T}_{\mathrm{ad}}=-\frac{\triangle \mathrm{H}_{\mathrm{ad}}}{\mathrm{RT}^{2}}
$$

where $\Delta \mathrm{H}_{\mathrm{ad}}$ is the enthalpy of adsorption. The integrated Vant Hoff equation used to estimate $\Delta \mathrm{H}_{\mathrm{ad}}$ :

$$
\operatorname{lnK} \mathrm{ad}=-\frac{\triangle \mathrm{H}_{\mathrm{ad}}}{\mathrm{RT}^{2}}+\text { constanst }
$$

may be used to estimate $\Delta H_{a d}$. It follows from equation (9) that, if the enthalpy is independent of temperature, a plot of $\ln \mathrm{K}$ against $\mathrm{T}^{-1}$ should be linear where $\Delta \mathrm{H}_{\mathrm{ad}}$ can be estimated. The connection between the entropy change of adsorption of $\mathrm{MB}$ when transfer from the bulk solution to the surface phase and the change in enthalpy, $\Delta \mathrm{H}_{\mathrm{a}}$ could be derived by the appropriate form of Gibbs- Helmholtz equation viz

$$
\Delta G=\Delta H+\left(T \frac{d}{d T}\right)_{p}
$$

where

$$
\left(\frac{d(\Delta G)}{d T}\right)_{p}=-\triangle S
$$

From which it follow the integral entropy of adsorption is given by

$$
\triangle S \neq \triangle H-\triangle G) / T
$$

Here $\Delta \mathrm{G}$ and $\Delta \mathrm{H}$ are obtained from equations (7) and (9), respectively.

The expression is a tool for assessing entropy change of $\mathrm{MB}$ adsorption when it is transferred from the bulk solution to the surface of acicular habit phase.

The thermodynamic definition of entropy change dS that occurs as a result of chemical change is based on the expression

$$
\mathrm{ds}=\frac{\mathrm{dq}_{\mathrm{q} e v}}{\mathrm{~T}}
$$

The definition above can be used to formulate an expression for the change in entropy of the surroundings, $\Delta \mathrm{S}_{\text {surr. }}$

Therefore, we can adapt the definition of entropy change in equation (12) as

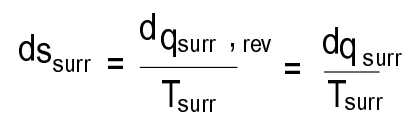

And because the temperature of the surroundings is constant whatever the changes, it is assumed that the heat can be transformed reversibly and isothermally, so that

$$
\Delta s_{\text {surr }}=\frac{q_{\text {surr }}}{T_{\text {surr }}}
$$

Regardless of how the change is brought about in the system reversibly or irreversibly, provided the surrounding remain in internal equilibrium, the change of entropy of the surrounding can be calculated by dividing the heat transfer by the temperature at which the transfer takes place. Equation (15) below makes it simple to calculate the change in entropy of the surrounding that accompany any process because at constant pressure, q equals $\Delta \mathrm{H}$, thus 


$$
\frac{q_{\text {surr }}}{T}=\frac{\triangle H}{T}
$$

So that total entropy, $\Delta \mathrm{S}_{\text {tot }}$ is

$$
\triangle S_{\text {tot }}=\Delta S_{\text {sys }}+\triangle S_{\text {surr }}
$$

With the above assertion, $2^{\text {nd }}$ law of thermodynamic could be verified to identify the mechanism of adsorption and/or whether one state is accessible for another by a spontaneous change.

\section{RESULTS AND DISCUSSION}

\section{Composition and $X$-ray identification}

Percentage purity determined as iron content was $95.9 \%(61 \pm 0.02 \% \mathrm{Fe})$. Particle size was estimated from the density of the habit and estimated surface areas were between 0.2 and 0.19 nm.

Prominent peaks $(\AA)$ observed from X-ray diffraction powder patterns with corresponding d-values for $\alpha_{1}+\alpha_{2} / 2(\AA)$ were at 4.18 (4.20), 3.41 (3.36), 2.70 (2.69), 2.45 (2.44), 2.25, (2.25), 2.01 (2.09), 1.92 (1.92), 1.80 (1.80), 1.72 (1.72), 1.56 (1.50), 1.51 (1.46) and 1.39 (1.32). The entries agree satisfactorily within brackets obtained in literature [11]. However, the presence of $\beta$-goethite in the sample at $3.70 \AA$, probably explain the high percentage Fe in acicular sample as earlier worker had also indicated $[12,13]$.

\section{IR analysis/absorption by vaporous pyridine}

The important infrared absorption frequencies (spectrum not shown) are given in Table 1. Absorption band at 793 and $870 \mathrm{~cm}^{-1}$ are the lattice $\mathrm{O}-\mathrm{H}_{\text {bending }}$ vibration [14] in addition to 599 $\mathrm{cm}^{-1}$ for $\mathrm{Fe}-\mathrm{O}_{\text {strech }}$ characteristic of $\alpha$-goethite [15]. In this acicular spectrum, these bands are apparently at 780 and $517 \mathrm{~cm}^{-1}$ (Table 1). These lattice vibrations at the lower frequencies are higher than the frequencies normally observed for $\alpha$-goethite. The lattice vibration couple with sorbed water vibration and gives rise to the high frequencies because sorbed water peak, which have been observed in this work. The absorption band at $3413 \mathrm{~cm}^{-1}$ for neat acicular sample is assigned to free surface $\mathrm{OH}_{\text {group }}$. This is similar to what was observed by Rochester and Topham [16] and Russell et al. [17] between $3660-3500 \mathrm{~cm}^{-1}$ for dried sample. The band at $3100 \mathrm{~cm}^{-1}$ was assigned to bulk $\mathrm{OH}_{\text {stretch }}$ in consonance with Russell et al. [17] entries. The residual absorption band at $1620 \mathrm{~cm}^{-1}$ is also assigned to $\mathrm{HOH}$ for sorbed water as observed by Nakamoto [18] and Russell et al. [17]. This analysis was able to compliment and/or discriminate $\beta$-goethite presence as observed at $666 \mathrm{~cm}^{-1}$ in line with Landa and Gast [14] entry at $680 \mathrm{~cm}^{-1}$.

The absorption of vapourous pyridine was also used to distinguish the type of acid sites on the acicular sample by IR absorption spectra of adsorbed pyridine on the solid. The assignment of the frequencies was made in accordance with Parry [19] and Delafosse [20]. The bands at 1543 and $1637 \mathrm{~cm}^{-1}$ due to pyridinium ions could be attributed to Bronsted acidity, while in the region of pyridine bending mode, 1459 and $1509 \mathrm{~cm}^{-1}$ are due to coordinatively bonded pyridine, thus characteristic of Lewis acidity. It is therefore safe to say that acicular sample contain electron accepting sites (Lewis acid) and (proton donor) site. According to Parfitt et al. [21] exposed ferric ions in this case act as Lewis acid sites.

Furthermore, this assignment is in accordance with Ward [22] where the band at $1545 \mathrm{~cm}^{-1}$ was indicated as Brosted site and at $1450 \mathrm{~cm}^{-1}$ as Lewis acid site. 
Table 1. Selected IR absorption bands and their assignment for acicular habit.

\begin{tabular}{|c|c|c|}
\hline Analysis type & Peak position $/ \mathrm{cm}^{-1}$ & Assignments \\
\hline \multirow{9}{*}{$\begin{array}{l}\text { IR absorption } \\
\text { for neat acicular }\end{array}$} & $780 \mathrm{~m} 517 \mathrm{w}$ & $\mathrm{Fe}-\mathrm{O}_{\text {str }}$ frequencies \\
\hline & $861 \mathrm{w}$ & $\mathrm{O}-\mathrm{H}_{\text {str }}$ frequencies \\
\hline & $1043 \mathrm{w}, 1107 \mathrm{w}, 1118 \mathrm{w}$ & $\mathrm{Fe}-\mathrm{O}_{\mathrm{w}}$ asymmetric stretch \\
\hline & $1456 \mathrm{~m}$ & $\mathrm{O}-\mathrm{H}_{\text {bend }}$ \\
\hline & $1619 \mathrm{~m}$ & $\delta(\mathrm{HOH}), \mathrm{H}_{2} \mathrm{O}$ of crystallization. \\
\hline & $2343 \mathrm{w}, 2931 \mathrm{w}$ & Intramolecular $\mathrm{H}-\mathrm{OH}$ frequencies. \\
\hline & $3413 \mathrm{~b}$ & Surface $\mathrm{OH}_{\text {str }} \mathrm{H}_{\text {bonding }}$ interaction \\
\hline & $3100 \mathrm{w}$ & Bulk $\mathrm{OH}_{\text {group }}$ \\
\hline & $666 \mathrm{w}$ & $\mathrm{Fe}-\mathrm{O}_{\text {str }}$ for $\beta$-goethite \\
\hline Vaporous pyridine & 1543,1637 & Bronsted acid sites \\
\hline Absorption & 1459,1509 & Lewis acid sites \\
\hline
\end{tabular}

b-broad, m-medium, w-weak bands.

\section{Shape of the isotherms}

The apparent isotherms for the adsorption of MB onto the acicular $\alpha$-goethite surface, which is a measure of the net effect on the concentration of the solution rise less steeply at low equilibrium concentrations are shown in Figure 1. These isotherms are of type S-shape [23], convex upward curves considered to correspond to strong adsorption showing define plateau of constant adsorption at high concentrations, leading to the assumption by analogy that the plateau do represent complete monolayer coverage of the surface by a monolayer of solute (MB). These isotherms indicate a tendency for large adsorbed molecule to vertically adsorbed and associate rather than as an isolated unit. It is also evident that adsorption capacity increases rapidly from 4.7 to $27.2 \times 10^{-5} \mathrm{M}$ for the equilibrium concentration of 0.13 to $1.90 \times 10^{-5} \mathrm{M}$ at $25{ }^{\circ} \mathrm{C}$. At higher temperature of $30{ }^{\circ} \mathrm{C}$, there was also an increase in adsorption capacity to a maximum of $33.1 \times 10^{-5} \mathrm{M}$ for equilibrium concentration of $2.74 \mathrm{M}$. A drop in adsorption capacity was observed at higher temperature of $35{ }^{\circ} \mathrm{C}$. At $35{ }^{\circ} \mathrm{C}$ curve, a maximum appears at $31.0 \mathrm{M}$ before constant plateau. There is however one difference, and that is the small drop in the height of the plateau from $33.1 \mathrm{~mol} / \mathrm{g}$ at $30{ }^{\circ} \mathrm{C}$ to $32.2 \mathrm{~mol} / \mathrm{g}$ at $25{ }^{\circ} \mathrm{C}$. At $35{ }^{\circ} \mathrm{C}$ the curve does show a minimum in contrast with $30{ }^{\circ} \mathrm{C}$ and $25{ }^{\circ} \mathrm{C}$, and at low concentration, the equilibrium concentration of the solute is in several order of magnitude lower than the rest and so the values of the amount adsorbed.

By analogy with Langmuir type isotherm, the difference in height of the plateau at the three different temperatures suggests the values of the equilibrium constants for the adsorption processes are not close. In all, adsorption capacity decrease with increase in temperature is a behavious typical of exothermic adsorption.

Considering the molecular structure of $\mathrm{MB}$, it is possible that the orientation of this molecule on the surface of solid could be dependent on temperature, and different orientation might explain the result found in this work. At $25{ }^{\circ} \mathrm{C}$, the orientation of $\mathrm{MB}$ in the surface could lead to a lower adsorption capacity when compare with that of $30^{\circ} \mathrm{C}$ and perhaps delay adsorption capacity at $35^{\circ} \mathrm{C}$ as shown in Figure. 1

\section{Adsorbent characterization}

The surface area occupied per molecules of $\mathrm{MB}, \mathrm{A}_{\mathrm{m}}$, onto the acicular habit surface was estimated on the assumption that the monolayer of adsorbed MB is not exceeded at the 
equilibrium concentration considered. Table 2 below gives the estimated specific surface area (S) and monolayer $\left(\mathrm{X}_{\mathrm{m}}\right)$ at three different temperatures.



Figure 1. Apparent isotherm for the adsorption of MB onto acicular habit of $\alpha$-goethite at various temperatures.

Table 2. Estimated surface properties and thermodynamics quantities $\left(A_{m}=73 \AA\right)$.

\begin{tabular}{|c|c|c|c|c|c|c|c|}
\hline $\mathrm{T} / \mathrm{K}$ & $\begin{array}{c}\mathrm{X}_{\mathrm{m}} \\
(\mathrm{mol} / \mathrm{g}) 10^{5}\end{array}$ & $\begin{array}{c}\mathrm{S} \\
\left(\mathrm{m}^{2} / \mathrm{g}\right)\end{array}$ & $\begin{array}{c}\Delta \mathrm{H} \\
(\mathrm{kJ} / \mathrm{mol})\end{array}$ & $\begin{array}{c}\Delta \mathrm{G} \\
(\mathrm{kJ} / \mathrm{mol})\end{array}$ & $\begin{array}{c}\Delta \mathrm{S}_{\text {syst }} \\
(\mathrm{J} / \mathrm{mol} / \mathrm{k})\end{array}$ & $\begin{array}{c}\Delta \mathrm{S}_{\text {total }} \\
(\mathrm{J} / \mathrm{mol} / \mathrm{k})\end{array}$ & $\begin{array}{c}\text { Pore } \\
\text { vol.cm } / \mathrm{g}\left(10^{4}\right)\end{array}$ \\
\hline 298 & 32.40 & 141.00 & -11.88 & -6.66 & -37.02 & 22.33 & 1.95 \\
\hline 303 & 33.30 & 146.00 & -11.88 & -6.93 & -37.30 & 28.15 & 1.82 \\
\hline 308 & 31.40 & 137.00 & -11.88 & -6.48 & -35.25 & 21.05 & 1.35 \\
\hline
\end{tabular}

This value of $73 \AA^{2}$ as indicated in Table 2 is reasonable enough to be accounted for by an adsorbate molecule oriented vertically, adsorbed edgewise on the acicular habit as also observed by Giles et al. [24] for graphitised carbon.

The specific surface area estimated was within the range of $135-144 \mathrm{~m}^{2} / \mathrm{g}$. At $25{ }^{\circ} \mathrm{C}$ to 30 ${ }^{\circ} \mathrm{C}$, there is an increase in specific surface area, but not at $35^{\circ} \mathrm{C}$ which fall below $140 \mathrm{~m}^{2} / \mathrm{g}$. Beside surface area, pore volume is also an important characteristic as shown in Table 2. At higher temperature of $35{ }^{\circ} \mathrm{C}$ there is dramatic decrease of pore volume. This is expected as already shown in the Figure 2 whereby apparent adsorption decreases with increase in temperature. The decrease in pore volume decrease the adsorption capacity at $35{ }^{\circ} \mathrm{C}$ hence, it decreases the distribution of surface area. 


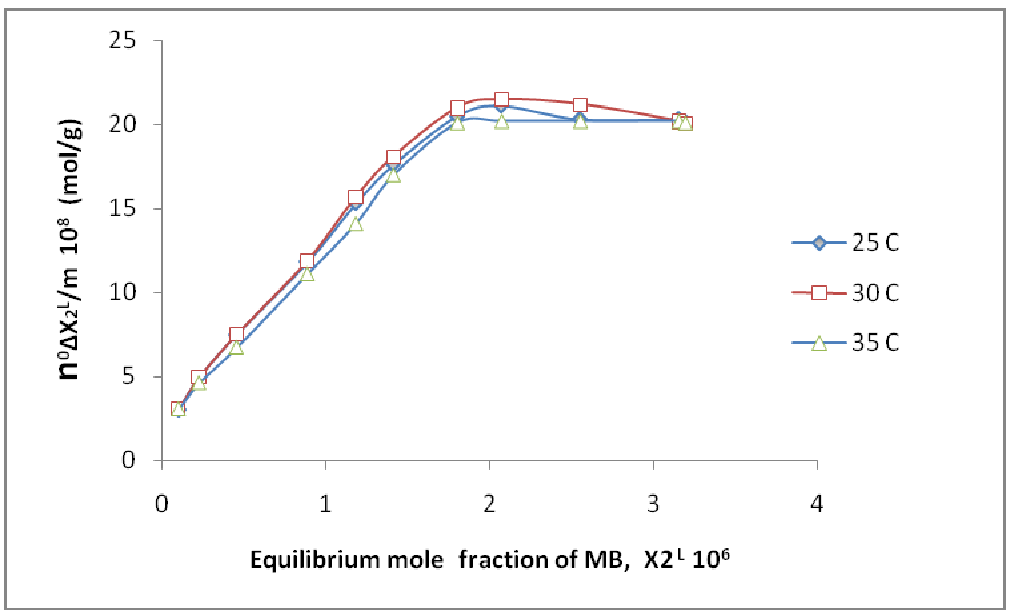

Figure 2. Composite isotherms for the system MB/glycerol adsorbed onto acicular habit at various temperatures.

Sorption isotherm studies

The adsorption data were analyzed with the help of the linear form of Lagmuir, Freundlich and Temkin isotherm. The three linearised isotherms equation are given in Eqs (17-19): Langmuir equation:

$$
\theta^{-1}=K_{L}^{1}+K_{L}^{2} C_{e}^{-1}
$$

Freundlich equation:

$$
\log \theta=\log k_{f}+1 / n \log C_{e}
$$

Temkin equation:

$$
\theta=B \ln A+B \ln C_{e}
$$

where $\Theta$ is the degree of surface coverage by the adsorbed molecule, $\log \mathrm{K}_{\mathrm{f}}$ is roughly a measure of the adsorption effectiveness, $\mathrm{C}_{\mathrm{e}}$ is the equilibrium concentration of $\mathrm{MB}$ in $\mathrm{mol} / \mathrm{L}$ The $\mathrm{K}_{\mathrm{L}}{ }^{1}$ and $\mathrm{K}_{\mathrm{L}}{ }^{2}$ are the Langmuir constants representing the adsorption energy and adsorption strength/intensity evaluated from slope and intercept respectively at temperatures 25,30 and 35 ${ }^{\circ} \mathrm{C}$. A and B are the Temkin isotherm constants. The values of all parameters were obtained from the linear correction between $\log \Theta$ as a function of $\log C$ for Freundlich, $\Theta^{-1}$ as a function of $\mathrm{C}_{\mathrm{e}}^{-1}$ for Langmuir, and $\Theta$ as a function of $\mathrm{C}_{\mathrm{e}}$ for Temkin. Linear regression lines were developed using the add trend line function of Microsoft Excel.

The estimated parameter for the different model and related correlation coefficients are shown in Table 3. The correlation coefficient $\left(r^{2}\right)$ determines the extent of applicability of a given isotherm (how well the model represent the data, and thus measures the strength of the linear relationship). These isotherms fit well to the experimental data as shown in Table 3. 
Table 3. Langmuir, Freundlich and Temkin isotherm constants.

\begin{tabular}{|c|c|c|c|c|c|c|c|c|c|}
\hline Temp & \multicolumn{3}{|c|}{ Langmuir } & \multicolumn{3}{c|}{ Freundlich } & \multicolumn{3}{c|}{ Temkin } \\
\hline $\mathrm{T} / \mathrm{K}$ & $\begin{array}{c}\mathrm{K}_{\mathrm{L}}^{2} \\
(\mathrm{~mol} / \mathrm{g})\end{array}$ & $\begin{array}{c}\mathrm{K}_{\mathrm{L}}^{1} \\
\mathrm{~L} / \mathrm{mol}^{-5}\end{array}$ & $\mathrm{r}^{2}$ & $\mathrm{~K}_{\mathrm{f}}\left(10^{3}\right)$ & $\mathrm{n}^{-1}$ & $\mathrm{r}^{2}$ & $\begin{array}{c}\mathrm{A} \\
\mathrm{L} / \mathrm{mol}\left(10^{6}\right)\end{array}$ & $\begin{array}{c}\mathrm{B} \\
\left(10^{5}\right)\end{array}$ & $\mathrm{r}^{2}$ \\
\hline 298 & 38.430 & 1.060 & 0.973 & 7.000 & 1.703 & 0.973 & 1.619 & 9.000 & 0.936 \\
\hline 303 & 38.120 & 1.010 & 0.972 & 6.000 & 1.634 & 0.957 & 0.533 & 9.000 & 0.923 \\
\hline 308 & 36.140 & 1.090 & 0.902 & 3.000 & 1.608 & 0.967 & 1.619 & 9.000 & 0.909 \\
\hline
\end{tabular}

Langmuir isotherm also fit the data. However, the values $\mathrm{K}_{\mathrm{L}}{ }^{2}$ increase for a decrease in solution temperature, an indication of the improvement of adsorption with decrease in temperature. The observed $\mathrm{K}_{\mathrm{L}}{ }^{2}$ values could be an indication that the theoretical adsorption capacity corresponds to a saturated monolayer of adsorbate molecules on acicular habit surface with a continuous energy distribution on the habit surface. The Langmuir constant $\mathrm{K}_{\mathrm{L}}{ }^{1}$ (adsorption energy) apparently is temperature independent, meaning that the adsorption energy of $\mathrm{MB}$ does not vary over the surface and also seem not to change as the solution temperature changes.

Temkin isotherms provide information about the speciation of adsorption energy (heterogeneity) of the adsorbing surface. The isotherm assumes that the adsorption energy decreases linearly with surface coverage due to adsorbate/adsorbent interactions, thus heterogeneity of the adsorbing surfaces. Fitting of the data into Temkin model seem to discriminate different energies, thus heterogeneity of the acicular habit surface.

The Freundlich constants as observed in Table 3 for $\mathrm{K}_{\mathrm{f}}$ decrease with increasing temperature of solution from 25 to $35^{\circ} \mathrm{C}$. The decreasing temperature confirms that the adsorption process is exothermic. It has also shown that the value of $1 / \mathrm{n}$ is greater than unity and decreases as temperature increases. This result appears to dispose of earlier suggestion that the quantity $1 / \mathrm{n}$ is generally less than unity [25]. The deviation from unity could be attributed to the molecular interaction among the adsorbed species.

\section{Thermodynamics of adsorption}

In order to investigate some thermodynamic parameters of the adsorption, the Gibbs energy $\left(\Delta \mathrm{G}_{\mathrm{a}}\right)$, the entropy $\left(\Delta \mathrm{S}_{\mathrm{a}}\right)$ and the enthalpy $\left(\Delta \mathrm{H}_{\mathrm{a}}\right)$ were determined, thus enabling qualitative interpretation of adsorption characteristic, for it is possible to predict correct mechanism.

Table 2 shows the calculated values for $\Delta \mathrm{G}_{\mathrm{a}} \Delta \mathrm{H}_{\mathrm{a}}$ and $\Delta \mathrm{S}_{\mathrm{a}}$. The $\Delta \mathrm{G}_{\mathrm{a}}$ values are higher, negative and for a start decrease from 25 to $35{ }^{\circ} \mathrm{C}$ and then increase at $35{ }^{\circ} \mathrm{C}$. The negative values of $\Delta \mathrm{G}_{\mathrm{a}}$ indicate spontaneity of the adsorption of $\mathrm{MB}$ on the acicular habit and stability of the adsorbed layer on the habit surfaces. The $\Delta \mathrm{G}_{\mathrm{a}}$ values are $<40 \mathrm{~kJ} / \mathrm{mol}$, which indicates that physisorption was the predominant mechanism in the adsorption process of MB on acicular habit.

The negative values of $\Delta \mathrm{H}_{\mathrm{a}}$ show the exothermic (heat is released from the adsorption process) nature of the adsorption process of $\mathrm{MB}$ which may signifies either physisorption or chemisorptions. Typically, adsorption enthalpy of physisorption is lower than $40 \mathrm{~kJ} / \mathrm{mol}$, while that of chemisorptions may approach $100 \mathrm{~kJ} / \mathrm{mol}$. In this work, absolute value of $11.90 \mathrm{~kJ} / \mathrm{mol}$ obtained indicates that mode of binding is physisorption.

In order to further support physisorption, the value of activation energy $\left(\mathrm{E}_{\mathrm{a}}\right)$ was calculated with the aid of Arrhenius equation [10]. The low value of activation energy indicates that the adsorption present a low potential energy barrier.

The $\Delta \mathrm{S}_{\text {syst }}$ values are as well negative throughout, but with apparent initial increase with increasing surface coverage on acicular habit from 25 to $30{ }^{\circ} \mathrm{C}$, and then decrease significantly 
at $35{ }^{\circ} \mathrm{C}$. In every case, $\Delta \mathrm{S}_{\mathrm{a}}$ decreases at higher temperature imply strengthening of adsorbateadsorbent interaction and increasing randomness at the solid/liquid interface during the sorption of MB on onto Acicular sample.

When both surrounding and system are consider, a positive $\Delta S_{\text {tot }}$ are obtained with increment from 25 to $30{ }^{\circ} \mathrm{C}$ and then decrease at $35^{\circ} \mathrm{C}$. We therefore infer that in the course of spontaneous change $\left(\Delta \mathrm{S}_{\mathrm{a}}>0\right)$, not only did the transition exothermic and spontaneous as earlier indicated but irreversible. This fit in with the $2^{\text {nd }}$ law of thermodynamic i.e. the entropy of an isolated system $>0$.

Further investigations have established the extent of microporosity on the surface of acicular sample as shown in Table 2 ranging from 1.25-2.00 $\times 10^{-4} \mathrm{~cm}^{3} / \mathrm{g}$. The micropore volume decreases with temperature. By analogy with surface area, the decrease is in line with decrease in apparent adsorption (Figure 2) of $\mathrm{MB}$ at higher temperature of $35{ }^{\circ} \mathrm{C}$. Hence it decreases the distribution of surface area at $35^{\circ} \mathrm{C}$, otherwise the decreases in pore volume with decrease in temperature increases the total volume of the sample, hence the distribution of surface area increase. In all, the maximum result of pore volume was achieved at $25^{\circ} \mathrm{C}\left(1.95 \times 10^{-4} \mathrm{~cm}^{3} / \mathrm{g}\right)$.

\section{Surface excess}

The results are shown in Figure 2. These isotherms gave the surface excess of MB in the adsorbed layer, $\mathrm{n}^{0} \Delta \mathrm{X}_{2}^{\mathrm{L}} / \mathrm{m}$. The surface excess given by these composite isotherms for two components system is related to the concentration of each component at the surface and it obeys the equation:

$$
\mathrm{n}_{\mathrm{O}} \Delta \mathrm{x}_{2}^{\prime}=\mathrm{n}_{1}^{\mathrm{s}} \mathrm{x}_{2}^{1}-\mathrm{n}_{2}^{\mathrm{s}} \mathrm{x}_{1}^{\prime}
$$

where $\Delta \mathrm{X}_{2}{ }^{\mathrm{L}}$ is the decrease in the mole fraction of $\mathrm{MB}$ in the bulk liquid 1, when $0.01 \mathrm{~g}$ of the habit are brought into contact with $\mathrm{n}^{0}$ mole of original solution; $\mathrm{X}_{2}^{\mathrm{L}}$ and $\mathrm{X}_{1}^{\mathrm{L}}$ are the mole fraction of $\mathrm{MB}$ and glycerol adsorbed per $\mathrm{g}$ acicular habit respectively in the bulk liquid at equilibrium; and $\mathrm{n}_{2}{ }^{\mathrm{s}}$ and $\mathrm{n}_{1}{ }^{\mathrm{s}}$ are the amount of $\mathrm{MB}$ and glycerol adsorbed per acicular habit respectively. Equation (20) is based simply on a material balance between the bulk liquid and the adsorbed phase and it applied to adsorption from any solution over all range of concentration [26]. These composite isotherms adopt the Type 2 individual isotherm in the Schay and Nagy classification [26] with apparent "kink" in the isotherms between $\sim 1.8$ and .07 $\mathrm{x} 10^{-6} \mathrm{M}$ equilibrium concentrations shown in Figure 2 . The figure shows that there is preferential adsorption of $\mathrm{MB}$ which tends to be greater at $30{ }^{\circ} \mathrm{C}$ system and is sensitive to temperature but merges at high mole fraction of $\mathrm{MB}, \mathrm{X}_{2}{ }^{\mathrm{L}}$ at some stages as the adsorption progresses. At higher temperature, the isotherm tends to constant values. In addition, the composite becomes almost identical with the apparent isotherm (Figure 2) expressing the adsorption of solute only and correspond to an almost complete MB monolayer.

These isotherms at three different temperature shows the surface excess of the MB in the adsorbed layer, $\mathrm{n}^{0} \Delta \mathrm{X}_{2}^{\mathrm{L}} / \mathrm{m}$, on assumption that only solute was adsorbed, the interaction between the surface of the habit and solvent (glycerol) is the same as that of pure solvent and that the surface of the adsorbent is completely covered by the adsorbate at all concentrations.

\section{CONCLUSIONS}

The preceding discussion showed that the adsorption of $\mathrm{MB}$ on acicular $\alpha$-FeOOH habits is exothermic reaction driven by increase in entropy. The estimated thermodynamics quantities reflect, in general, changes in the configuration of the adsorbate and weak interaction of the adsorbate molecules with the adsorbent surface. 
Although the thermodynamics results do not generally imply any adsorption mechanism, it is possible to advance some concept that would be in qualitative agreement with the results obtained. The adsorption isotherms can be well described with Freundlich and Temkin equation indicating the heterogeneity of the habit surface coverage.

We therefore conclude that this habit is significantly different from twin habit earlier published in terms of surface coverage, thermodynamic parameter and apparent adsorption isotherm for acicular is more sensitive to temperature presumably all equilibrium concentration. Even though the two habits follow Dubinins isotherm but the acicular habit display high pore volume compare with that of twin habit. Still the surfaces of both habits are heterogeneous if the location of recognized Lewis and Bronsted site are adsorption sites.

\section{REFERENCES}

1. Atkinson, R.J.; Posner, A.M.; Quirk, J.P. J. Inorg. Nucl. Chem. 1968, 30, 2371.

2. Barton, S.S. Carbon 1987, 25, 343.

3. Zubairu, S.M.J.; Harrison, G.F.S.; Uzairu, A.; Iyun, J.F. African J. Pure Appl. Chem. 2009, 3,42 .

4. Gregg, S.J.; Sing, K.S.W. The Physical Adsorption of Gases by Nonporous Solids: The Type II Isotherms in Adsorption Surface Area and Porosity, Academic Press: London; 1982; $\mathrm{p}$ 41.

5. Brunauer, S.; Emmett, P.H.; Teller, E.J. J. Amer. Chem. Soc. 1938, 60, 309.

6. Thomas, J.M. Thomas, W.J. Introduction to Principle of Heterogeneous Catalysis, 4th ed., Academic Press: London; 1967; p 88.

7. Everett, D.H. Trans. Farad. Soc. 1964, 60, 1803.

8. Groszek, A.J. J. Chromatogr. 1960, 3, 454.

9. Crisp, D.J. J. Colloid Sci. 1956, 11, 356.

10. Atkins, P.W. Physical Chemistry, 6th ed., Oxford University Press: Oxford; 1998, pp 225, 857

11. Heller, W.; Peters, J. J. Colloid. Interf. Sci. 1970, 32, 592.

12. Murad, E. Clay Minerals 1979, 14, 273.

13. Mackay, A.L. Mineralog. Mag. 1960, 32, 545.

14. Landa, E.R.; Gast, R.G.; Clays Clay Miner. 1973, 21, 121.

15. White, W.B.; Roy, R. Amer. Miner. 1964, 49, 1670.

16. Rochester, C.H.; Topham, S.A. J. Chem. Soc. Farad Trans I 1979, 75, 591.

17. Russell, J.D.; Parfitt, R.L.; Fraser, A.R.; Farmer, V.C. Nature 1974, 248, 220.

18. Nakamato, K. Infrared Spectra of Inorganic and Coordination Compounds, 3rd ed., Wiley Interscience: New York; 1978; p 226.

19. Parry, E.P. J. Catal. 1963, 2, 371.

20. Delafosse, D; Kermarec, M; Briend-Faure, M. J. Chem. Soc. Farad. Trans. I 1974, 70, 2180.

21. Parfitt, G.D.; Russell, J.D.; Farmer, V.C. J. Chem. Soc. Farad. Trans. I 1976, 72, 1082.

22. Ward, J.W. J. Catal. 1968, 11, 271.

23. Giles, C.A.; MacEwen, T.H.; Nakhwa, S.N.; Smith, D. J. Chem. Soc. 1960, 3973.

24. Giles, C.H.; Mehta, H.V; Stewart, C.E.; Subramanian, R.V.R. J. Chem. Soc. 1954, 4360.

25. Glasstone, S. Textbook of Physical Chemistry, 2nd ed., Macmillan: London; 1956; pp 829, 1196.

26. Kipling, T.J. Adsorption from Solutions of Non-electrolyte, Academic Press: London; 1965; p 26. 